\title{
Understanding Seniors' Choices in Medicare Advantage
}

\author{
Amal N. Trivedi, MD, MPH ${ }^{1,2}$ \\ 'Department of Health Services, Policy and Practice, Brown University, Providence, RI, USA; ${ }^{2}$ Providence VA Medical Center, Providence, RI, USA.
}

$\mathrm{J}$ Gen Intern Med 31(2):151-2

DOI: $10.1007 / \mathrm{s} 11606-015-3511-3$

(c) Society of General Internal Medicine 2015

$\mathrm{S}$ everal years ago, a family member asked me to help with decisions about her Medicare coverage. Even though I am a general internist who studies health policy, the complexity of this apparently straightforward task surprised me. Between Part D and Medicare Advantage (MA) plans, there were dozens of options available. Identifying the best one required a thorough understanding of her medical conditions, current physicians, regular medications, retirement savings, and income. Premiums were straightforward to understand, but predictions about the amount of physician copayments or the likelihood of incurring a hospital deductible were more uncertain. Traditional Medicare offered unfettered choice of physicians, but no cap on out-of-pocket spending. In contrast, MA plans offered an out-of-pocket spending cap but constrained the network of providers. No single Part D formulary included all of my relative's medications in its preferred tier. Only after many visits to Medicare's website and careful inspection of insurance plan directories did we reach a tentative selection.

This experience is not uncommon among Medicare's 54 million enrollees, who confront a complex, growing, and often daunting set of choices about coverage and benefits. The average Medicare beneficiary can choose from among 30 Part D prescription drug plans and 18 Medicare Advantage (MA) plans. ${ }^{1,2}$ MA plans, which enrolled approximately $30 \%$ of all Medicare beneficiaries in 2015, have the flexibility to deviate from Medicare's standard benefit package, cover additional services, restrict the network of available providers, and require pre-authorization to receive some types of care. ${ }^{3}$ Enrollees must therefore consider premiums, cost-sharing, covered services, provider networks, and the plan's quality. Ideally, beneficiaries would revisit their decisions annually, since benefits among plans, as well as seniors' health needs, change over time.

The proliferation and complexity of coverage options in Medicare represents a "feature" rather than a "bug" of prevailing federal health policy thinking, which emphasizes market competition and consumer choice. Under this view, increased choice among competing private insurers will improve the quality of care, reduce health care spending, and satisfy consumers' varied preferences for optimal coverage. In an efficient market, insurers strive to lower the price of their product and

Published online September 11, 2015 improve quality, and informed, rational consumers will reward firms that successfully achieve these objectives.

However, is it reasonable to assume that Medicare beneficiaries will operate as the rational consumers described in standard economics textbooks? Insights from behavioral economics and emerging empirical evidence suggest otherwise. From trivial decisions among jams in a supermarket to consequential ones about retirement investments, increasing the number and complexity of options can erode decision-making or lead to an individual making no choice at all. ${ }^{4}$ As an example, over fourfifths of Medicare enrollees in the Part D program could have selected a more generous plan at a lower cost. ${ }^{5}$ If seniors had selected optimally, their spending on prescription drugs would be $31 \%$ lower compared to their spending in the plan they actually chose. Beneficiaries with lower cognitive ability fare particularly poorly in Medicare's insurance markets. Such beneficiaries are less likely to enroll in a supplemental insurance plan to reduce their out-of-pocket medical expenses ${ }^{6}$ or respond to more generous benefits and lower premiums among Medicare Advantage plans. ${ }^{7}$ Another problem relates to decisional inertia or "stickiness". Once enrolled in a plan, seniors persevere in that option, even when switching would save them substantially. ${ }^{5}$ This evidence casts doubt about whether seniors, at least in the current environment, can reliably identify and select insurance options that maximize protection from financial risk at the lowest price.

Ideally, Medicare beneficiaries should consider quality in addition to cost in their plan decisions. To facilitate seniors' choices among MA plans, the Centers for Medicare and Medicaid Services (CMS) developed a five-star rating system that incorporates over 50 separate quality measures. CMS also employs these ratings to assign MA payment bonuses. While condensing many measures of quality into a composite score may sacrifice important detail, a single measure has more intuitive appeal and poses less cognitive burden for consumers. Of note, the five star ratings are ubiquitous and highly influential in settings outside healthcare (Amazon, Google, Netflix, TripAdvisor, and Yelp all use five-star rating scales), but there is limited evidence examining how seniors interpret star ratings and how they negotiate cost-quality tradeoffs in their selection of MA plan options.

In this issue of the Journal of General Internal Medicine, Reid and colleagues examined the predictors of plan selection among newly enrolled Medicare Advantage beneficiaries in $2011 .^{8}$ They employed a rigorous discrete choice model that includes the full set of available MA plan options for each beneficiary and produces the marginal "willingness to pay" for a better plan star rating. The model explained about onefifth of the variation in plan choices among their cohort. 
Reid et al. report that the most important determinant of plan choice in their model was the MA plan's market share, which accounted for $35 \%$ of the explained variation. The cost variables of premium and out-of-pocket spending explained $25 \%$ and $12 \%$, respectively. Star ratings accounted for substantially less of the explained variation (14\%) than did market share or the cost variables. The authors speculate that brand market share may convey aspects of quality, such as reputation and word-of-mouth. Or perhaps plans with larger market share have more robust physician networks, an attractive feature to many MA beneficiaries. The smaller contribution of star ratings is not surprising, and may relate to uncertainty about the usefulness of the ratings or perhaps a general lack of awareness.

How much were beneficiaries willing to pay for a higher star rating? In a particularly provocative finding, the marginal willingness-to-pay declined from $\$ 549$ in annual costs to go from a 2.5 to a 3 -star plan, to just $\$ 68.22$ to move from a 4.5 to a 5-star plan. This finding suggests that avoiding the plan with the worst ranking may be a more powerful motivator than joining the plan in first place. ${ }^{9}$ Beneficiaries may also have less confidence that higher star ratings capture the elements of quality that are most personally relevant.

The association between star ratings and willingness to pay was lower among black enrollees, those residing in rural areas, and those younger than 64 (who are more likely to have a disability). This finding raises the concern that public reporting could exacerbate disparities if minority, disabled, or rural beneficiaries are less able to select higher-quality plans.

The authors lacked information on some potentially important determinants of plan choice in Medicare Advantage. The plan's physician network is a key consideration for seniors, especially for those with chronic conditions or complex health care needs. Unfortunately, national data on the scope of networks in MA plans are not available. MA plan network directories list their contracted providers, but recent reports have detected widespread inaccuracies in these directories, particularly in areas where physicians have received immediate termination letters from MA plans in the middle of the year. ${ }^{10} \mathrm{CMS}$ could consider reporting comprehensive, standardized information about MA plan networks to assist beneficiaries in their selection of plans, and audit these data regularly for accuracy.

Another potentially important predictor of plan choice may be an enrollee's source of coverage before becoming Medicare-eligible. In the coming years, new entrants to the Medicare program will have increased familiarity with the features of managed care insurance, either through employer-based coverage or through the Affordable Care Act's health insurance exchanges. Perhaps these individuals will be more receptive to Medicare Advantage and more experienced in sorting through diverse coverage options. New entrants to Medicare may also exhibit brand loyalty. For instance, a newly insured
Medicare beneficiary who previously received commercial insurance coverage from "ACME Health Plan" may be more likely to enroll in ACME's Medicare Advantage product when she turns 65.

Recent health reform efforts, both in the Medicare program and under the Affordable Care Act, have required individuals to evaluate the costs and quality of a complex set of coverage options and make informed choices. This study by Reid et al. suggests that quality ratings may influence enrollment decisions in the Medicare Advantage market, though market share, premiums, and out-of-pockets costs seem to be stronger predictors. Much important work remains toward understanding and optimizing Medicare enrollees' insurance choices. Seniors' decisions about insurance coverage have important consequences with regard to their protection from financial risk, promoting access to care, and maximizing the value of Medicare spending.

Acknowledgments: Dr. Trivedi was supported by the National Institute on Aging (Grant Nos. RO1 AG-044374 and P01 AG-027296) and reports consulting for the Merck Manual. The views expressed in this article are those of the author and do not necessarily reflect the position or policy of the Department of Veterans Affairs or the US government.

Corresponding Author: Amal N. Trivedi, MD, MPH; Department of Health Services, Policy and Practice, Brown University, Providence, RI, USA (e-mail: amal_trivedi@brown.edu).

\section{REFERENCES}

1. Hoadley J, Cubanski J, Hargrave E, Summer L. Medicare Part D: a first look at plan offerings in 2015. Available at: http://kff.org/medicare/issuebrief/medicare-part-d-a-first-look-at-plan-offerings-in-2015/. Accessed August 21, 2015.

2. Jacobson G, Damico A, Neuman T, Gold M. Medicare advantage 2015 data spotlight: overview of plan changes. Available at: http://kff.org/ medicare/issue-brief/medicare-advantage-2015-data-spotlight-overviewof-plan-changes/. Accessed August 12, 2015.

3. Keohane LM, Grebla RC, Mor V, Trivedi AN. Medicare advantage members' expected out-of-pocket spending for inpatient and skilled nursing facility services. Health Aff (Millwood). 2015;34(6): 1019-27.

4. Schwartz B. More isn't always better. Harv Bus Rev. 2006;84(6):22.

5. Abaluck J, Gruber J. Choice inconsistencies among the elderly: evidence from plan choice in the Medicare Part D program. Am Econ Rev. 2011;101(4):1180-1210.

6. Chan S, Elbel B. Low cognitive ability and poor skill with numbers may prevent many from enrolling in Medicare supplemental coverage. Health Aff (Millwood). 2012;31(8): 1847-54.

7. McWilliams JM, Afendulis CC, McGuire TG, Landon BE. Complex Medicare advantage choices may overwhelm seniors-especially those with impaired decision making. Health Aff (Millwood). 2011;30(9):1786-94.

8. Reid RO, Deb P, Howell BL, Conway PH, Shrank WH. The roles of cost and quality information in Medicare Advantage plan enrollment decisions: an observational study. J Gen Intern Med. 2015. doi:10.1007/s11606015-3467-3.

9. Kuziemko I, Buell R, Reich T, Norton MI. Last-place averson: evidence and redistributive implications. Q J Econ. 2014;129:105-149.

10. Resneck JS Jr, Quiggle A, Liu M, Brewster DW. The accuracy of dermatology network physician directories posted by Medicare Advantage health plans in an era of narrow networks. JAMA Dermatol. 2014;150(12):1290-7. 